\title{
Alpha-1-antitrypsin associated liver disease in rheumatoid arthritis
}

\author{
L.G. Teh, M.M. Steven and H.A. Capell \\ Centre for Rheumatic Diseases, 35 Baird Street, Glasgow, UK.
}

\begin{abstract}
Summary: Two cases of alpha-1-antitrypsin associated liver disease occurring in patients with rheumatoid arthritis are described. Both presented with abnormal liver function tests and the true diagnosis was only apparent after liver biopsy and detailed serological studies. The concurrence of these two conditions is noteworthy because of the postulated role of proteolytic enzymes in producing the characteristic cartilaginous erosions of rheumatoid arthritis.
\end{abstract}

\section{Introduction}

Alpha-1-antitrypsin (A1-AT), a glycoprotein synthesized in the liver, is the major serum inhibitor of a wide range of proteolytic enzymes. Low levels of A1AT are found in people with the $\mathrm{ZZ}, \mathrm{MZ}$ and PZ phenotypes and are associated with childhood cirrhosis, emphysema of early adult onset, and more recently cryptogenic cirrhosis in adults (Triger \& Milward-Sadler, 1979). Although the low levels of A1AT associated with these phenotypes could theoretically be implicated in the pathogenesis of rheumatoid arthritis (Cox \& Huber, 1976), typing studies have shown conflicting results (Sjöblom \& Wolheim, 1977). We wish to report two patients with rheumatoid arthritis and liver diseases associated with the $\mathrm{MZ}$ phenotype and low serum levels of A1-AT.

\section{Case reports}

\section{Case 1}

A 47 year old hypertensive man with a nine year history of sero-positive rheumatoid arthritis was found to have abnormal liver function tests. Bilirubin was $25 \mu \mathrm{mol} 1$ (normal 3-22), aspartate transaminase (AST) $68 \mathrm{U} / 1$ (normal 12-48), alanine aminotransferase (ALT) $66 \mathrm{U} / 1$ (normal 8-55), alkaline phosphatase $654 \mathrm{U} / 1$ (normal 80-280), gamma glutamyl transpeptidase transferase (GGT) $163 \mathrm{U} / 1$ (normal $<36$ ). He admitted to drinking approximately $210 \mathrm{~g}$ of alcohol a week. Current drug therapy included

L.G. Teh, M.B., Ch.B.; M.M. Steven, M.B., Ch.B., M.R.C.P.; H.A. Capell, M.B., Ch.B., M.R.C.P.

Correspondence: L.G. Teh.

Accepted: 10 January 1984 indomethacin, nadolol, prazosin and glyceryl trinitrate. Examination showed nodules ànd active synovitis of many joints. Spider naevi were noted on the chest and bilateral Dupuytren's contractures, palmar erythema and hepatosplenomegaly were also present. Hepatitis B surface antigen ( $\mathrm{HBsAg}$ ), antinuclear antibody, smooth muscle antibody and anti-mitochondrial antibody were not detected. An isotope liver scan showed hepatosplenomegaly in keeping with parenchymal liver disease and portal hypertension. A liver biopsy showed micronodular cirrhosis with moderate amounts of fat present. There was ballooning of hepatocytes but no Mallory bodies were seen and the pattern was considered a low grade chronic active hepatitis and not related to alcohol consumption. In addition, PAS positive diastase resistant globules were noted in the liver cells (Fig. 1), and immunoperoxidase staining showed these globules to contain A1-AT. The serum level of Al-AT was $1.2 \mathrm{~g} / \mathrm{l}$ (range 1.0-2.5 g/l). Genetic typing revealed the phenotype MZ.

\section{Case 2}

A 62 year old woman with a four year history of seronegative rheumatoid arthritis was found to have elevated alkaline phosphatase $(880 \mathrm{U} / 1)$ and gammaglutamyl transferase $(68 \mathrm{U} / 1)$. She had previously received several non-steroidal anti-inflammatory drugs and was currently on flurbiprofen and had also commenced penicillamine $125 \mathrm{mg}$ daily because of progression of disease. There was no history of previous liver disease, but she admitted to alcohol consumption of approximately $140 \mathrm{~g}$ a week over the previous seven years. Examination showed active synovitis in her fingers, shoulders and knees. Hepato 


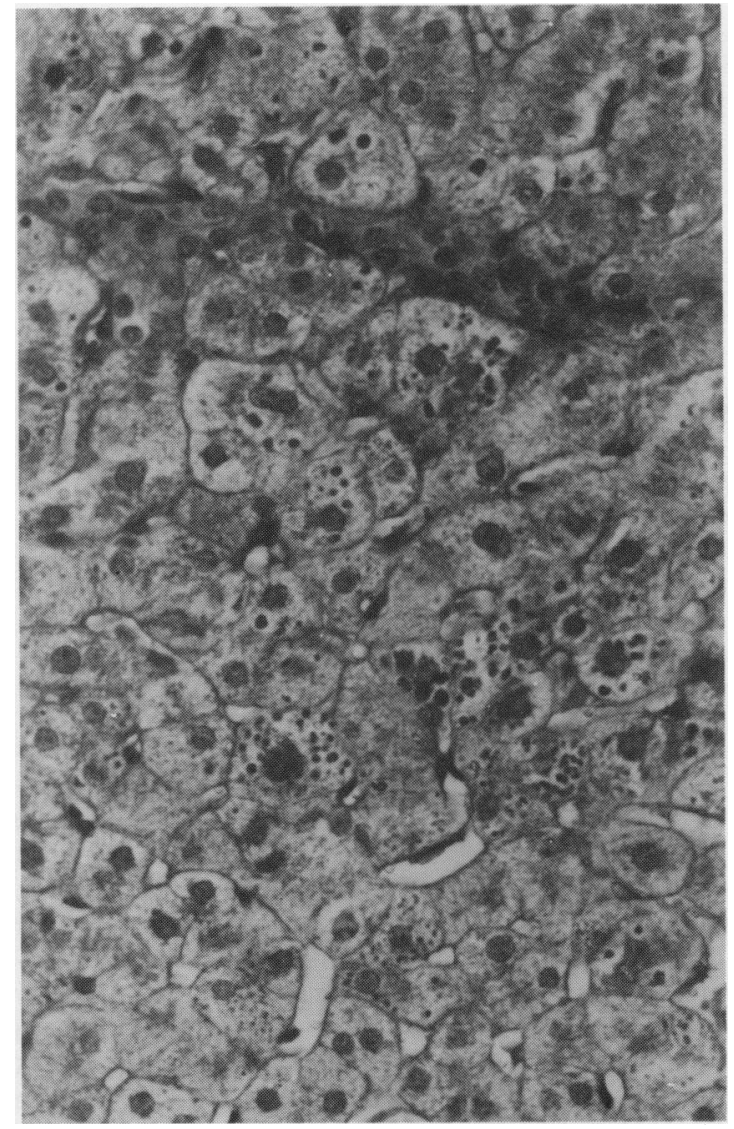

Figure 1 Al-AT granules are shown within a number o: hepatocytes but predominantly periportal. PAS/dias. tase $\times 460$.

splenomegaly was present but no other stigmata of chronic liver disease were detected. Serology (as in Case 1) was negative and an isotope liver scan showed hepatomegaly and patchy uptake of isotope with a normal spleen. A liver biopsy showed no evidence of acute or chronic liver disease but numerous PAS

\section{References}

COX, D.W. \& HUBER, O. (1976). Rheumatoid arthritis and alpha-1-antitrypsin. Lancet, i, 1216.

GEDDES, D.M., WEBLEY, M., BREWERTON, D.A., TURTON, C.W., TURNER-WARWICK, M., MURPHY, A.H. \& MILFORD-WARD, A. (1977). Alpha-1-antitrypsin phenotypes in fibrosing alveolitis and rheumatoid arthritis. Lancet, ii, 1049.

HODGES, J.R., MILWARD-SADLER, G.H. \& WRIGHT, R. positive, diastase resistant globules were present in the periportal hepatocytes. Immunoperoxidase staining confirmed this to be A1-AT. The serum level of A1-AT was $1.3 \mathrm{~g} / \mathrm{l}$ with $\mathrm{MZ}$ phenotype.

\section{Discussion}

Deficiency of the protease inhibitor A1-AT found in the $\mathrm{Z}$ phenotypes could theoretically result in destruction of joint cartilage. In fact elevated levels of A1-AT, an acute phase reactant are more often seen. Studies of $\vec{\circ}$ Al-AT phenotype in arthritis produced conflicting $\overrightarrow{\vec{\omega}}$ results (Cox \& Huber, 1976; Sjöblom \& Wolheim, 㝏 1977; Geddes et al., 1977) but A1-AT deficiency would 8 not appear to be pathogenetically important in the 3 majority of patients with rheumatoid arthritis. Minor os abnormalities of liver function are frequent in rheumatoid arthritis but the prevalence and cause of $\vec{N}$ chronic liver disease in this condition are unknown. One case of rheumatoid arthritis was noted among $61 \beth$ cases of A1-AT associated liver disease (Hodges et al., 우 1982). In these cases, serum A1-AT was inappropriate- ly low, characteristic globules were found in the liver TT and both were $\mathrm{MZ}$ phenotype. Although drugs or $\frac{\mathbb{O}}{\mathrm{O}}$ alcohol consumption could be contributory, the features are more suggestive of A1-AT deficient liver $₹$ disease.

It is unlikely that A1-AT deficiency is of relevance to o the pathogenesis of most cases of rheumatoid arthrit but careful investigation of patients with liver dysfunction is warranted. It is important to distinguish this entity from other causes of chronic liver disease such as chronic active hepatitis, alcoholic liver disease and $\frac{\circ}{\varnothing}$ drug induced conditions with their differing implications for prognosis and treatment.

\section{Acknowledgements}

We wish to thank Dr A. Milford Ward, Department of Immunology, Royal Hallamshire Hospital for A1-AT phen- $\bar{\sigma}$ otyping, Professor R.W.M. MacSween for providing photographs of the histology and Mrs M. Tucker for typing the manuscript.

(1982). Chronic active hepatitis: the spectrum of disease. N Lancet, i, 550.

SJÖBLOM, K.G. \& WOLHEIM, F.A. (1977). Alpha-1-antitryp- 옹 sin phenotypes and rheumatic diseases. Lancet, ii, 41.

TRIGER, D.R. \& MILWARD-SADLER, G.H. (1979). Alpha-1- ㅇ antitrypsin deficiency and liver disease. In Liver and Biliary Disease, Wright, R., Alberti, K.G.M.M., Karran, S. \& $\frac{\mathscr{C}}{\Phi}$ Milward-Sadler, G.H. (eds), p. 805. London: Saunders. 